disease. In the cases of bronchopneumonia above referred to oxygen was given at first by the usual funnel method. This, lowever, suffers from many disadrantages: the presence, of a nurse is necessary; much oxygen is wasted owing to rapid diffusibility; it is donbtful whether the inspired air has a much raised oxygen tension; and the presence of a large funnel in close proximity to the face is often resented by a restless patient. These are all difficulties which it is essentia to overcome in the production of an apparatus. which will usefully administer oxygen. An oxygen chamber is, of course, ideal, for the oxygen tension can be exactly regulated. It is a luxury, however, which is restricted to a few institutions of sufficient wealth, and even in them it can only be used in a small proportion of cases, so that the lesser hospitals and the private practitioner must look else where.

Description of Apparatuts.

The diagram is nearly sufficiently explanatory of the apparatus which forms the subject of the present communica

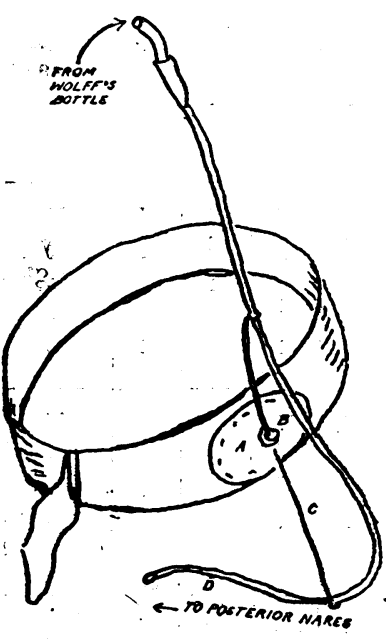
tion. A webbing or elastic circlet, whose size can be regulated by a buckle, grips the head firmly but not tightly. On- the front of this is an aluminium plate, $A$, which acts as a firm base for the brass pin B. Through a vertical hole in this passes an aluminium rod, c, which can be fixed at any level by a screw. Loops at the extremities of this hold a rubber catheter (size 6), D; they grip it but allow it to be pulled through to any de sired length.. Oxygen passes from the cylinder through a Wolff's 'bottle eontrining fluid (water or brandy) and standing in a bowl holding warm water. From this it passes to the patient, who receives it in tranasa!ly through the rubber catheter.

Method of Use.

Attention to a few details is necessary when fitting the apparatus to a patient. 'I'ic catheter must first be lubricated, and the best ointment for this has been found to be novocain 2 per cent. in vaseline; it should be inserted to the level of the posterior nares, or a little beyond, but must not touch the posterior pharyngeal wall. If a thread be tied round the catheter to mark the depth to which it is desired to iltroduce this; a nurse can easily see whether any slipping has occurred and can quielsly and accuratel y readjust it. The lower loop in the aluminium wire should be as near the nostril as possible. The rubber tube to which the catheter is attached can be suspended, in which case the movements of the patient's head are quite unrestricted. 'The rate of flow of oxygen can be seen by the rapidity of the bubbles through the brandy or the water in the Wolff's bottle, and the speed need be no faster than about 70 to 80 bubbles a minute. Oxygenation is efficient at a much slower rate of flow than with an open funncl.

\section{Mechanical Advantages.}

The apparatus is a stable one. Since it moves with each movement of the head the patient is not worried, and soon becomes reconciled to it, eventually forgetting its presence. It is very liglit and portable. Oxygen is conducted to a position whence much of it is inspired; there is thus actually a very considerable saving in the amount of oxygen used. It is inexpensive.

Clinical Advantages.

It has been used in twenty-three cases of severe bronchopneumonia in children. Cyanosis is not seen in cases using it. in Sleep is not interfered with. There is no increase in the number of paroxysms in cases of bronchopneumonia in pertussis; there is thus no local irritation from its presence. Other signs of irritation or resentment are not seen, as a rule, a!though occasionally it has been found necessary to tio the hands down. Oxygen can be given continuously and indefinitely in an effective and econonical manner.
There appears to be no reason why its use should be re stricted to childrep ; they provide the more searching test and success with them should promise at least an equal success in adult cases. It should prove of use in any pulmonary or cardiac condition complicated by anoxaemia and cyanosis. The instrument is made by Messrs. Maw, Son and Sons, of Aldersgate Street, who have agreed that all profits from its sale should go to the East London Hospital tor Children.

\section{TREATMENT OF PSORIASIS BY MANGANESE.}

$$
\text { BY }
$$

JAMES MOORE, F.R.C.S.EDIN. BEI.FAST.

THE only specific treatment of psoriasis, up to the present; is the external use of chrysophanic ointment. Arsenic is useful in anaemic cases, sodium salicylate in cases with a rheumatic history, and thyroid extract in the obese or those with symptoms of hypothyroidism. These improre the disease by improving the patient's general health, but have no specific action.

In the autumn of $1920 \mathrm{I}$ had under treatment two cases of chronic staphylococcic infection, who at the same timo suffered from well-marked psoriasis. After six injections of gradually increasing doses of staphylococcic vaccine, my paticui informed me that the shin was better than it had been for years. I continucd the vaccine for another six ivjections, but with no appreciable improvement in the psoriasis.

The well-kuown benefit derived from the use of intramuscular injections of collosol maugariese in staphylococcic infections, also the fact that collosol mariganese, like stà phylococcus vaccine, will bring about an acute recrudescence of streptococcal eczema, suggested its use to me in these two cascs. The results were very satisfactory: one was cleared up completely after four injections, and the other after eight.

I have treated in all 35 cases of psoriasis in the past twenty months, of which the following is typical of the procedure adopted.

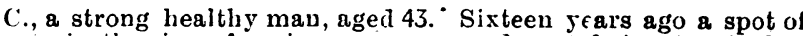
psoriasis, the size of a sixpence, appeared on left leg, two inche above the external malleolus. In six months the disesse had spread to the knee, and entirely suriounded the les. After three years the other (risht) les was attacked ill a similar manner years a the (rix years a the disease appeared in the lumbar region, and extender became affected, and it extended on both arms almost to the wrist joint on the extensor surfaces. About six months before conjoint on the extensor surfaces. About six months before consulting me a pat

inguinal region.

Such was his condition when he consulted me on January 6th. 1922. With the usual autiseptic prccautions, I injected into the deltoid muscle (left. arm) $1 / 2$ c.cm. collosol manganese $(1 / 4 \mathrm{c.cm}$. No. 1 sol., $1 / 4 \mathrm{ccm}$. No. 2 sol. (Crookes), mixed in syringe) and ordered him to use vaseline to assist in removal of the scales, and allay the irritation: On January 10 th $1 / 2 \mathrm{c} . \mathrm{cm}$. collosol manginese was injected into the right deltoid; on the $17 \mathrm{th} 1 \mathrm{c.cm}$. into the was injected into the right deltoid; on the 17th 1 c.cm. iuto the left deltoid ; on the $24 \mathrm{th} 1 \mathrm{c.cm}$. into the right deltoid; aud on the
$31 \mathrm{st} 1 \mathrm{c.cm}$. into the left deltoid. On this last date the inguinal $31 s t 1$ c.cm. into the left deltoid. On this last date the inguinal
patch had almost disappeared, and on the back and elbows islets of healthy skin were showing in the centre of patches

On February 7 th 1 c.cm. collosol mangauese was again injected ; the inprovement continued. On February 14th a further $1 \mathrm{c.cm}$ : was injected. On this date, with the exception of a small patch about two inches square, the disease had entirely vamislied. l continued the weekly. injections of $1 \mathrm{ccm}$. collosol manganese up to the end of March, when the patient was completely cleareri. In all the patient received thirteen injections. Vaseline was the In all the patient 1

From my study of psoriasis and its treatment by collosol manganese I have arrived at the following conclusions:

1. The chinical appearance and behayiour of psoriasis snggest a spirochaetal origin, but neithei salvarsan, its congeners, nor mercury have any beneficial effect on the disease.

2. Mixed staphylococcic vaccine will improve the lesions, but will not bring about their complete disappearance, without the use of chrysophanic ointment.

3. Collosol manganese will clear up the disease in from six to sixteen intramuscular injections without the assistance of ay external treatment. I prescribe vaseline where there is much irritation.

4. From the action of staphylocoecic vaccine, and especially collosol mauganese, I would suggest that psoriasis is probably due to a special staphylococcus, or at least bears an intimate relationship to chronic staphylocóccic iujection.

. The disease is, in my opinior, auto-inoculable.

6. $\Lambda$ number of cases in the same family can be accounted for by living under the same eonditions, and subject to the same infectiou: rather than by heredily. 